\title{
Validated Hptlc Method For Simultaneous Determination Of Metformin Hydrochloride And Glibenclamide In Combined Dosage Form
}

\author{
Mr. Sanjay S. Malgundkar ${ }^{1}$, Dr. Saira Mulla ${ }^{2} *$ \\ ${ }^{1,2}$ Shri Jjt University, Vidyanagari, Churu-Jhunjhunu Road, Chudela, District-Jhunjhunu, Rajasthan-333001
}

\begin{abstract}
This paper describes a simple, accurate and precise HPTLC method for simultaneous determination of Metformin Hydrochloride and Glibenclamide in a bulk as well as in the combined dosages form. During optimization of Mobile phases different solvents viz. butanol, methanol and triethylamine were tried. However resolution between metformin hydrochloride and Glibenclamide was not proper. A mobile phase of Methanol: Water: $0.4 \%$ sodium sulphate in water (7: 5:11) was developed for the densitometric determination of the drug products. Aluminum plate coated with the silica Gel $60 F_{254}$ was used as stationary phase. UV spectra were taken in the range of $190 \mathrm{~nm}$ to $400 \mathrm{~nm}$. Densitometric evaluation of the separated bands of Metformin hydrochloride and Glibenclamide was performed at $232 \mathrm{~nm}$ and at $238 \mathrm{~nm}$ respectively. The Rf values of Metformin hydrochloride and Glibenclamide were 0.27 and 0.80 respectively. Developed method was Linear over the range of $250 \mathrm{ng}$ to $1750 \mathrm{ng} / \mathrm{spot}$ and $250 \mathrm{ng}$ to $1750 \mathrm{ng} / \mathrm{spot}$ of Metformin hydrochloride and Glibenclamide respectively. Precision of the method was evaluated by calculating RSD for peak response by inerday and intraday analysis. Results were Interday RSD of peak response $=1.52 \%$ and Intraday RSD of peak response $=1.90 \%$ for Metformin hydrochloride. Similarly for Glibenclamide interday RSD of peak response $=1.67 \%$ and Intraday $R S D$ of peak response $=0.92 \%$. Accuracy was determined in terms of percentage recovery at three concentration levels for Metformin hydrochloride and for Glibenclamide. The results for metformin hydrochloride at three concentration levels are $95.79 \%, 97.84 \%$ and $96.06 \%$. In case of Glibenclamide the results are $96.0 \%, 97.03 \%$ and $96.53 \%$. Specificity was proved by spectral analysis of Metformin hydrochloride and Glibenclamide. There was no any interference of methanol being used as a diluents and mobile phase at the Rf values of Metformin hydrochloride and Glibenclamide. Standard spectrum and sample spectrum of Metformin hydrochloride and Glibenclamide were overlain to confirm Rf values. ICH guidelines were referred for Validation of an optimized method.
\end{abstract}

Keywords: High performance thin layer chromatography, microgram, nano gram, Metformin hydrochloride and Glibenclamide

\section{Introduction}

Metformin hydrochloride is chemically Imidodicarbonimidic diamide, N,N -Dimethyl,monohydrochloride, or 1,1-dimethyl biguanide monohydrochloride. Molecular formula is $\mathrm{C}_{4} \mathrm{H}_{11} \mathrm{~N}_{5}, \mathrm{HCl}$.CAS Number of metfromin hydrochloride is 1115-70-4 and molecular weight is 165.62

Metformin hydrochloride is an oral antidiabetic drug in the biguanide class. It is the first line drug of choice for the treatment of type 2 diabetes. It is effective for the overweight and obese people and those with normal kidney function. Its use in gestational diabetes has been limited by safety concerns. It is also used in the treatment of polycystic ovary syndrome and has been investigated for other diseases where insulin resistance may be an important factor. Metformin works by suppressing glucose production by the liver. Metformin is the only antidiabetic drug that has been shown to prevent the cardiovascular complications of diabetes. It helps reduce LDL, cholesterol and triglyceride levels, and is not associated with weight gain.

Glibenclamide is an antidiabetic drug in a class of medications known as sulfonylureas, closely related to sulfa drugs. The drug works by binding to and activating the sulfonylurea receptor 1 (SUR1), the regulatory subunit of the ATP-sensitive potassium channels $\left(\mathrm{K}_{\mathrm{ATP}}\right)$ in pancreatic beta cells. This inhibition causes cell membrane depolarization opening voltage-dependent calcium channel. This results in an increase in intracellular calcium in the beta cell and subsequent stimulation of insulin release.

After a cerebral ischemic insult the blood brain barrier is broken and Glibenclamide can reach the central nervous system. Glibenclamide has been shown to bind more efficiently to the ischemic hemisphere. Moreover, under ischemic conditions SUR1, the regulatory subunit of the $\mathrm{K}_{\mathrm{ATP}}$ and the $\mathrm{NC}_{\mathrm{Ca}^{-A T P}}{ }^{-}$ channels, is expressed in neurons, astrocytes, oligodendrocytes, endothelial cells and by reactive microglia.

It is used in the treatment of type 2 diabetes. It is one of the only two oral antidiabetics in the World Health Organization Model List of Essential Medicines (the other being metformin). 


\section{Validated Hptlc Method For Simultaneous Determination Of Metformin Hydrochloride And Glibenclamide In Combined Dosage Form}

It is 1-[[4-[2-[(5-Chloro-2-methoxybenzoyl) amino] ethyl] phenyl] sulphonyl]-3- cyclohexylurea. Molecular formula of Glibenclamide is $\mathrm{C}_{23} \mathrm{H}_{28} \mathrm{ClN}_{3} \mathrm{O}_{5} \mathrm{~S}$. Molecular weight is 494.0 and CAS number is 1023821-8

Literature survey reveals that several analytical methods have been reported for estimation of Metformin hydrochloride and Glibenclamide by High performance liquid chromatography and UV-VIS spectrophotometric method.

A simple, accurate and precise HPTLC method for simultaneous estimation of Metformin Hydrochloride and Glibenclamide tablets manufactured in the combined dosages form has been developed.<smiles>CN(C)C(=N)NC(=N)N</smiles>

(a)<smiles>COc1ccc(Cl)cc1C(=O)NCCc1ccc(S(=O)(=O)NC(=O)NC2CCCCC2)cc1</smiles>

(b)

Figure 1. : Molecular structure of Metformin Hydrochloride (a) Molecular Structure of Glibenclamide

(b)

\section{Materials and Methods}

\subsection{Chemicals and Reagents}

Metformin Hydrochloride and Glibenclamide working standards were provided by Aarti Drugs Ltd. and Cadilla pharmaceuticals Ltd. through Mr. Vikrant Tamse - Senior Manger Purchase as generous Gift samples for research work. Metformin hydrochloride, Glibenclamide Combination tablets were procured from the market. Analytical grade reagents were used during analytical method development and validation.

\subsection{Instrumentation}

In this paper, an analytical method for simultaneous estimation of Metformin hydrochloride and Glibenclamide has been developed and validated by referring $\mathrm{ICH}$ guidelines. The method was validated on CAMAG make HPTLC instrument. The stages in HPTLC are independent of each other. This includes application of samples on the precoated plate, development of plate in a twin trough CAMAG Chamber, evaporation of the mobile phase on CAMAG make hot plate, scanning of the developed plates and densitograms etc. Multi components can be analysed in a single analysis. This is the most important feature of this analytical technique over the other analytical techniques. A variety of mobile phases can be developed by using different solvents with different compositions. The mobile phase is being evaporated before the detection step. Application of sample solution and standard solution is simultaneously being done on the same plate.

CAMAG HPTLC instrument has CAMAG automatic TLC sampler 4 (ATS4) connected with the win CATS 4 software, CAMAG TLC scanner, Integrator controlled by win CATS4 Software. CAMAG twin trough glass chamber with stainless steel lid is being used for the development of the TLC. Precoated silica Gel 60 F254 on aluminum sheet is being used as the stationary phase.

During method development several mobiles phases were prepared for proper elution and resolution between Metformin hydrochloride and Glibenclamide. Chloroform, ethyl acetate and methanol in the different compositions were used as mobile phase. However there was no proper peak shape and resolution between Metformin hydrochloride and Glibenclamide. Hence mobile phase containing methanol, water and sodium sulphate were tried. Initially methanol and water in equal proportion was used and $1 \%$ sodium sulphate in water was used. The Rf value of Glibenclamide was more than 0.85 . Hence concentration of sodium sulphate was reduced to $0.5 \%$ and methanol ratio was increased. Finally proper peak shape and resolution was obtained at the mobile phase ratio Methanol: Water: $0.4 \%$ Sodium sulphate (7:5:11). In a $20 \mathrm{x} 10 \mathrm{~cm}$ twin trough glass chamber a linear ascending chromatographic development was carried out by using mobile phase, Methanol: Water and $0.4 \%$ Sodium sulphate in water (7:5: 11). The chamber was saturated for 40 minutes. The plates were developed in the CAMAG make twin trough TLC chamber upto $80 \mathrm{~mm}$. After development, TLC plate 


\section{Validated Hptlc Method For Simultaneous Determination Of Metformin Hydrochloride And Glibenclamide In Combined Dosage Form}

was dried in a current of hot air with the help of hair dryer and dried on a CAMAG hot plate for 5 minutes at $120^{\circ} \mathrm{C}$. A deuterium lamp was used in the UV range of $190 \mathrm{~nm}$ to $400 \mathrm{~nm}$ as a source of radiation.

A slit dimension was set at $6.00 \times 0.45 \mathrm{~mm}$, micro. Scanning speed was $20 \mathrm{mms}-1$ and data resolution at $100 \mu \mathrm{m} / \mathrm{step}$. Sample was spotted on the silica gel 60 F254 TLC plate by using CAMAG automatic TLC sampler 4 (ATS4). The contents of Metformin hydrochloride and Glibenclamide were evaluated by comparing the peak areas with linear regression.

\section{Standard Solution Preparation}

$10 \mathrm{mg}$ of Metformin hydrochloride and $10 \mathrm{mg}$ of Glibenclamide standards were separately weighed and transferred to the $10 \mathrm{~mL}$ volumetric flask. $2 \mathrm{~mL}$ of Methanol was added and sonicated for 5 minutes to dissolve the standards. Then diluted to $10 \mathrm{~mL}$ with methanol (Stock solution I and Stock solution II for Metformin hydrochloride and Glibenclamide respectively). $5 \mathrm{ml}$ from stock solution I and $5 \mathrm{~mL}$ from stock solution II were pipetted out in two separate volumetric flasks and diluted to $10 \mathrm{~mL}$ with methanol to obtain the concentration of $0.5 \mathrm{mg} / \mathrm{mL}$ of Metformin hydrochloride and $0.5 \mathrm{mg} / \mathrm{mL}$ and Glibenclamide respectively.

\section{Sample solution preparation}

Label claim of Metformin hydrochloride and Glibenclamide in the combined tablet dosage is $400 \mathrm{mg}$ and $2.5 \mathrm{mg}$ per tablet respectively. To determine the content, 10 tablets were individually weighed. Average weight was recorded. Tablets were crushed to make a uniform powder. A sample weight equivalent to $400 \mathrm{mg}$ of Metformin hydrochloride and $2.5 \mathrm{mg}$ of Glibenclamide was weighed, dissolved and diluted to $50 \mathrm{~mL}$ with methanol. Solution was filtered through whatman filter paper 41 to get the clear solution. Further $1 \mathrm{ml}$ was diluted to $10 \mathrm{ml}$ with methanol to obtain Metformin hydrochloride concentration $0.8 \mathrm{mg} / \mathrm{mL}$ and Glibenclamide concentration $0.005 \mathrm{mg} / \mathrm{mL}$.

\subsection{Validation of analytical method}

\section{Results and Discussions}

Analytical method was validated for Specificity, linearity, accuracy, precision, LOD, LOQ and Robustness.ICH guideline Q2 (R1) was referred for validation of an analytical method.

\subsubsection{Specificity}

Specificity was determined to ensure that there is no any interference of solvents being used in the mobile phase composition. Standard solutions of Metformin hydrochloride and Glibenclamide, sample, diluent and mobile phase were spotted on the TLC plate. TLC plate was developed in CAMAG twin trough chamber saturated with mobile phase. There was no any interference of Mobile phase and diluent at the Rf values of Metformin hydrochloride and Glibenclamide. The bands of Metformin Hydrochloride and Glibenclamide were confirmed by comparing Rf values and UV spectra of standard Metformin hydrochloride and Glibenclamide recorded at Peak start ( S) Peak apex(N) and peak end (E). The $R f$ values of Metformin hydrochloride and Glibenclamide were 0.27 and 0.80 respectively.

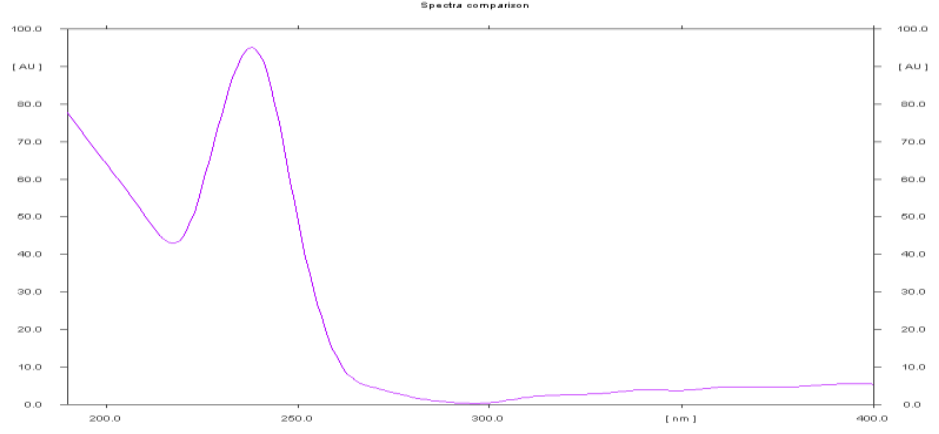

Figure 2 : UV spectra of standard Metformin hydrochloride 


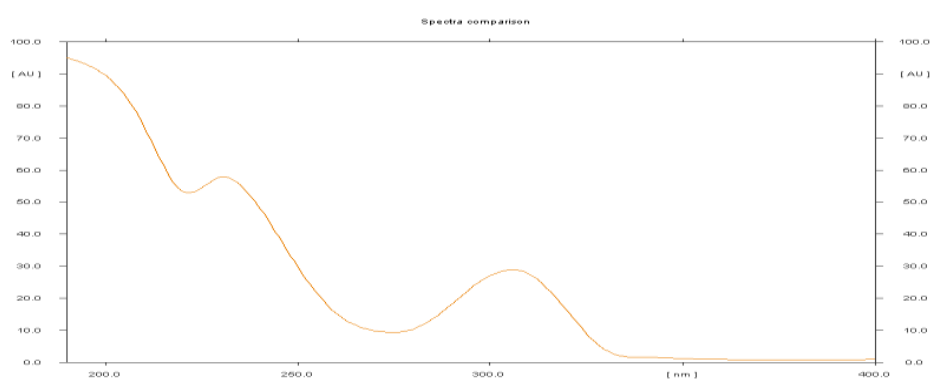

Figure 3 : UV spectra of standard Glibenclamide

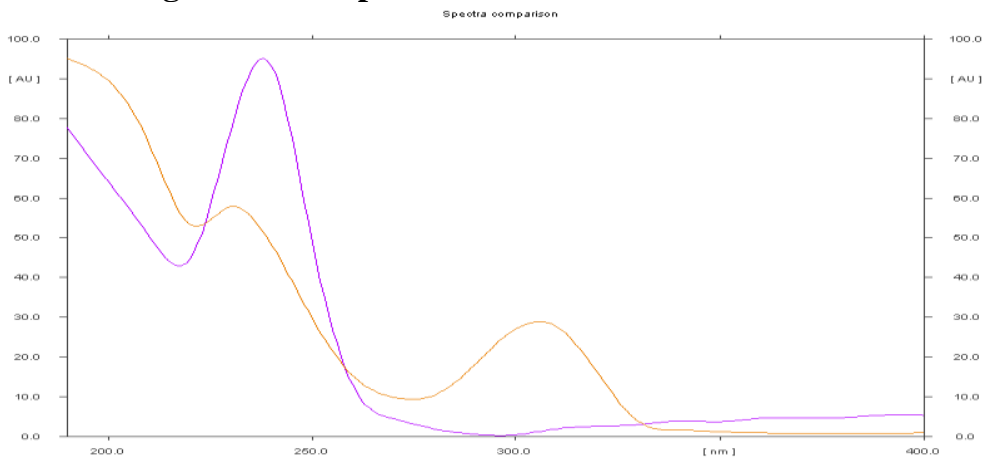

Figure 4: Overlain spectra Standard Metformin Hydrochloride and Glibenclamide

\subsubsection{Accuracy}

The accuracy of the Metformin hydrochloride and Glibenclamide was determined by performing percentage recovery. The known concentrations of the samples were spiked with the known concentrations of standard Metformin hydrochloride and Glibenclamide. The concentrations were $400 \mathrm{ng}, 500 \mathrm{ng}$ and $600 \mathrm{ng}$ of metformin hydrochloride and $800 \mathrm{ng}, 1000 \mathrm{ng}$ and $1200 \mathrm{ng}$ of Glibenclamide. The spiked samples were analysed referring the proposed analytical method. The percentage recovery was calculated and was in the range of $95.79 \%$ to $97.84 \%$ for Metformin hydrochloride and $96.0 \%$ to $97.03 \%$ for Glibenclamide respectively. The results are tabulated as under:

Table 1. : Percentage Recovery of Metformin Hydrochloride

$(\mathbf{n}=3)$

\begin{tabular}{|l|l|l|l|l|}
\hline $\begin{array}{c}\text { Sr. } \\
\text { No. }\end{array}$ & $\begin{array}{c}\text { Amount of Metformin } \\
\text { hydrochloride added in ng }\end{array}$ & $\begin{array}{c}\text { Amount of std. metformin } \\
\text { hydrochloride recovered in ng }\end{array}$ & \% Recovery & $\begin{array}{c}\text { \% Relative } \\
\text { standard Deviation }\end{array}$ \\
\hline 1 & 400 & 383.16 & 95.79 & 1.57 \\
\hline 2 & 500 & 489.20 & 97.84 & 0.16 \\
\hline 3 & 600 & 576.37 & 96.06 & 0.92 \\
\hline
\end{tabular}

Table 2: Percentage Recovery of Glibenclamide

$(\mathbf{n}=3)$

\begin{tabular}{|l|l|l|l|l|}
\hline $\begin{array}{l}\text { Sr. } \\
\text { No. }\end{array}$ & $\begin{array}{l}\text { Amount of std. } \\
\text { Glibenclamide added in ng }\end{array}$ & $\begin{array}{l}\text { Amount of Glibenclamide recovered } \\
\text { in ng }\end{array}$ & \% Recovery & $\begin{array}{l}\text { \% Relative } \\
\text { standard Deviation }\end{array}$ \\
\hline 1 & 800 & 768.00 & 96.0 & 0.48 \\
\hline 2 & 1000 & 970.30 & 97.03 & 0.43 \\
\hline 3 & 1200 & 1158.36 & 96.53 & 0.52 \\
\hline
\end{tabular}

\subsubsection{Precision}

The interday and intraday precision of the method were estimated by performing six determinations of Metformin hydrochloride and Glibenclamide standard solutions. The analysis was carried by referring the developed method. Analytical results obtained are tabulated as under:

Table 3: Precision for Metformin Hydrochloride

$$
(n=6)
$$

\begin{tabular}{|l|l|c|}
\hline Conc. of Metformin & Inter-day precision & Intra-day precision \\
\hline
\end{tabular}


Validated Hptlc Method For Simultaneous Determination Of Metformin Hydrochloride And Glibenclamide In Combined Dosage Form

\begin{tabular}{|c|c|c|c|c|}
\hline hydrochloride ( ng/band) & \multicolumn{2}{|c|}{} \\
\hline \multirow{2}{*}{1000} & Mean area ( AU) & \% RSD & Mean area ( AU) & \% RSD \\
\cline { 2 - 5 } & 6918 & 1.52 & 7240 & 1.90 \\
\hline
\end{tabular}

Table 4: Precision for Glibenclamide

$(n=6)$

\begin{tabular}{|c|c|c|c|c|}
\hline $\begin{array}{l}\text { Conc. of Glibenclamide } \\
\text { (ng/band) }\end{array}$ & \multicolumn{2}{|c|}{ Inter-day precision } & \multicolumn{2}{c|}{ Intra-day precision } \\
\hline \multirow{2}{*}{1000} & Mean area ( AU) & \% RSD & Mean area ( AU) & \% RSD \\
\cline { 2 - 5 } & 4638 & 1.67 & 4784 & 0.92 \\
\hline
\end{tabular}

\subsubsection{Robustness of the method}

During Robustness testing, small deliberate changes in the mobile phase composition were done. Effect on the results was examined. Mobile phase having different compositions were tried and chromatograms were run. The small change of $\pm 0.1 \mathrm{~mL}$ for each component of the mobile phase was done. $\pm 5 \%$ variation in the mobile during TLC development was used and chromatograph was run. Also saturation time was changed by \pm 5 minutes from the validated saturation time. The robustness of the method was determined at three different levels. The results are tabulated as under:

Table 5: Robustness testing

\begin{tabular}{|c|c|c|c|c|c|c|}
\hline \multicolumn{7}{|c|}{$(n=3)$} \\
\hline Parameter & $\begin{array}{c}\text { Conc. Level in ng } \\
\text { spot-1 of } \\
\text { Metformin } \\
\text { Hydrochloride } \\
\end{array}$ & $\begin{array}{c}\text { SD of Peak } \\
\text { response of } \\
\text { Metformin } \\
\text { Hydrochloride } \\
\end{array}$ & $\%$ RSD & $\begin{array}{c}\text { Conc. Level in ng } \\
\text { spot-1 of } \\
\text { Glibenclamide }\end{array}$ & $\begin{array}{c}\text { SD of Peak } \\
\text { response of } \\
\text { Glibenclamide }\end{array}$ & $\%$ RSD \\
\hline \multirow{3}{*}{$\begin{array}{l}\text { Mobile phase } \\
\text { composition } \\
( \pm 0.1 \mathrm{~mL})\end{array}$} & 500 & 50.0 & 1.39 & 750 & 43.466 & 1.86 \\
\hline & 750 & 72.947 & 1.33 & 1000 & 91.804 & 1.92 \\
\hline & 1000 & 52.041 & 0.75 & 1250 & 54.111 & 0.86 \\
\hline \multirow{2}{*}{$\begin{array}{l} \pm 5 \% \\
\text { variation in } \\
\text { mobile phase }\end{array}$} & 750 & 42.724 & 0.92 & 1000 & 60.178 & 1.69 \\
\hline & 1000 & 63.571 & 1.09 & 1250 & 96.106 & 1.80 \\
\hline \multirow{3}{*}{$\begin{array}{l} \pm 5 \text { Minutes } \\
\text { change in } \\
\text { saturation } \\
\text { time }\end{array}$} & 750 & 76.376 & 1.44 & 1000 & 75.056 & 1.82 \\
\hline & 1000 & 115.036 & 1.62 & 1250 & 47.014 & 0.89 \\
\hline & 1250 & 50.083 & 0.57 & 1500 & 103.040 & 1.66 \\
\hline
\end{tabular}

\subsubsection{Linearity:}

A series of standard solutions of Metformin hydrochloride and Glibenclamide were prepared. Standard solutions of Metformin hydrochloride and Glibenclamide were spotted on the TLC plate in the range of $0.5 \mu 1$ to $3.5 \mu \mathrm{l}$ respectively with the concentration of $0.250 \mathrm{mcg} / \mathrm{spot}$ to $1.750 \mathrm{mcg} / \mathrm{spot}$ respectively. The linear Correlation coefficient for Metformin hydrochloride is 0.9993 and correlation coefficient for Glibenclamide is 0 . 9998

\subsubsection{LOD and LOQ}

Calibration curve was plotted between concentration of Standard Metformin hydrochloride and Glibenclamide in range of $0.250 \mathrm{mcg}$ to $1.750 \mathrm{mcg} / \mathrm{spot}$ and corresponding peak responses. The limits of detection (LOD) and Limit of Quantitation (LOQ) were calculated from slopes of the calibration curve and standard deviation obtained for standard Metformin hydrochloride and Glibenclamide. The Limit of Detection and Limit of Quantitation obtained by this method for Metformin hydrochloride and Glibenclamide were LOD= $1.2412 \mathrm{mcg}, \mathrm{LOQ}=3.7613 \mathrm{mcg}, \mathrm{LOD}=0.9944 \mathrm{mcg}$ and $\mathrm{LOQ}=3.0133 \mathrm{mcg}$ respectively.

\subsubsection{Analysis of drug product:}

Experimental HPTLC results of the market samples of Metformin hydrochloride and Glibenclamide in a combine dosage form expressed as a $\mathrm{mg}$ of label claim were in good agreement with the label claim. The drug content was found to be $99.0 \%$ and $100.8 \%$ for Metforminn hydrochloride and Glibenclamide respectively. 


\section{Validated Hptlc Method For Simultaneous Determination Of Metformin Hydrochloride And Glibenclamide In Combined Dosage Form}

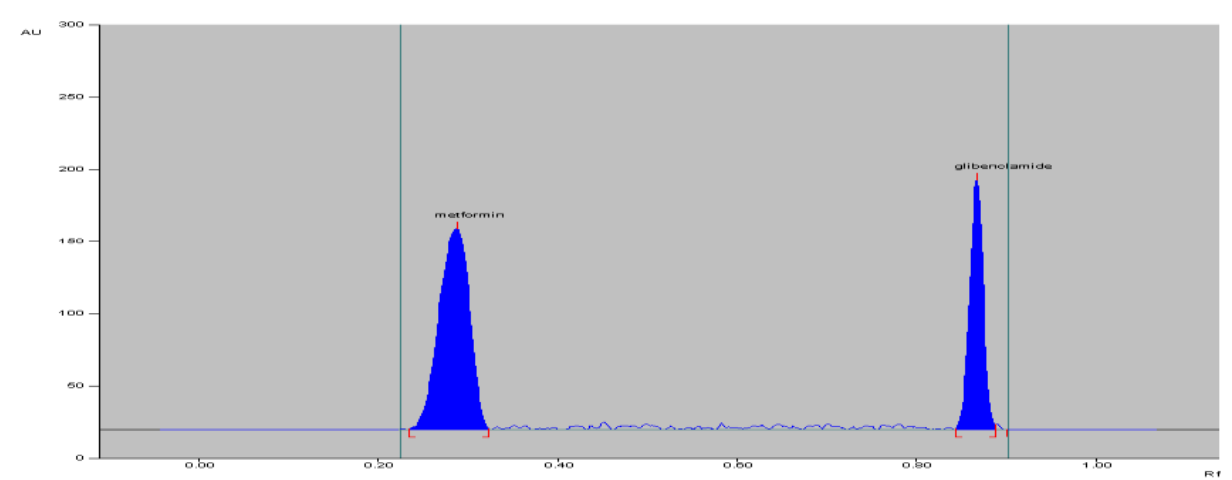

Figure 5.: Densitogram of Metformin hydrochloride and Glibenclamide

\subsubsection{Conclusion}

HPTLC analysis is rapidly becoming popular in routine analysis of drug substances and drug products. The advantages of these analytical techniques are low operating cost and high sample throughput. This method may be used in routine analysis for simultaneous determination of Metformin hydrochloride and Glibenclamide in drug substances as well as drug products. This method may be used for degradation study of the Metformin hydrochloride and Glibenclamide. The proposed HPTLC method is simple, accurate, economically chief and reproducible.

\subsubsection{Acknowledgement}

The Authors are thankful to Mr. Vikrant Tamse-Senior purchase Manager for providing working standards of Metformin hydrochloride and Glibenclamide required for the research work. The authors are also thankful to Mr. Shaharukh Bharucha -Senior Laboratory Manager- M/s Anchrom Testlab Pvt. Ltd. Mulund (E), Mumbai-400081 for providing support to carry an Analytical work at their well established Laboratory.

\section{References}

[1]. American Diabetes Association. Standards of medical care in diabetes-2009. Diabetes Care. 2009;32 Suppl 1:S13-61

[2]. Bailey CJ, Day C. Metformin: its botanical background. Practical Diabetes International. 2004;21(3):115-7.

[3]. Lord JM, Flight IHK, Norman RJ. Metformin in polycystic ovary syndrome: systematic review and meta-analysis. BMJ. 2003; 327(7421):951-3.

[4]. Marchesini G, Brizi M, Bianchi G, Tomassetti S, Zoli M, Melchionda N. Metformin in non-alcoholic steatohepatitis. Lancet. 2001; 358(9285):893-4.

[5]. Nair S, Diehl AM, Wiseman M, Farr GH Jr, Perrillo RP. Metformin in the treatment of non-alcoholic steatohepatitis: a pilot open label trial. Aliment Pharmacol Ther. 2004; 20(1):23-28.

[6]. Clinical Guidelines Task Force, International Diabetes Federation, Glucose control: oral therapy, In: Global Guideline for Type 2 Diabetes Brussels, International Diabetes Federation, 2007, 35-38.

[7]. National Collaborating Centre for Chronic Conditions, Type 2 diabetes: national clinical guideline for

[8]. management in primary and secondary care, London: Royal College of Physicians, 2008, 86.

[9]. NR Lad, SI Bhoir, IC Bhoir, M Sundaresan (2003) Indian J Pharm Sci 65(6):650-653

[10]. Madhukar A, Prince A, Vijay Kumar R, Sanjeeva Y, Jagadeeshwar K, et al. (2011) Simple And Sensitive Analytical Method Development And Validation Of Metformin Hydrochloride By RP-HPLC. Int Journal Pharm Pharm Sci 3: 117-120.

[11]. Lakshmi KS, Rajesh T, Sharma S (2009) Simultaneous Determination of Metformin And Pioglitazone By Reversed Phase Hplc In Pharmaceutical Dosage Forms. International journal of pharmacy and pharmaceutical sciences 1: 162-166.

[12]. Bhamare PC, Bari SB, Natarajan S, Patil AA, Patil SH, et al. (2011) Development And Validation Of A Precise Single Stability Indicating Hplc Method For Determinations Of Metformin Hydrochloride And Fenofibrate In Pure Form And In Pharmaceutical Tablets International Journal of PharmTech Research 3: 505-515.

[13]. Fatema K, Rahman Z, Haque T, Abul Kalam Azad M, Reza S (2010) Development And Validation of a Simple Method for Simultaneous Estimation of Metformin Hydrochloride and Gliclazide in Tablets by Using Reversed Phase High Performance Liquid Chromatography. J Pharm Sci 9: 83-89.

[14]. Rajesh T, Lakshmi KS, SharmaS, Lakshmi S (2009) Development and Validation of Liquid Chromatographic and UV Derivative Spectrophotometric Methods for the Determination of Metformin, Pioglitazone and Glimepiride in Pharmaceutical Formulations. Der Pharma Chemica 1: 238-246. 